\title{
Students' evaluation of preclinical simulation for all ceramic preparation (In Faculty of Dentistry Universiti Kebangsaan Malaysia)
}

\author{
Natasya Ahmad Tarib and Marlynda Ahmad \\ Department of Prosthodontics \\ Faculty of Dentistry, Universiti Kebangsaan Malaysia
}

\begin{abstract}
The purpose of the study is to evaluate all ceramic crown (ACC) preparations those were made by dental undergraduate students during the preclinical sessions. 104 plastic teeth were prepared by 4 th year dental undergraduates during the preclinical session for ACC crown examined. The teeth were placed on the frasaco arches and were mounted in the frasaco head. The preparations were examined for the tapering, presence of undercuts, incisal and cingulum reductions as well as preparation of shoulder margin. Preparations were examined using hand instruments and visual. The sample size was 92 plastic teeth. Most of the preparations were acceptable with acceptable placement and types of margins, adequate axial and incisal reductions and acceptable tapered of the axial walls. On the other hand, most of the teeth showed absence of cingulum wall. Most of the crowns prepared by the students were acceptable. It showed that they understood the principles of crown preparation. Cingulum wall preparation has to be given greater emphasis as it is important in the retention and resistance of the restoration.
\end{abstract}

Key words: crown preparation, all ceramic crown, preclinical simulation, skills

Correspondence: Natasya Ahmad Tarib, Department of Prosthodontics, Faculty of Dentistry Universiti Kebangsaan Malaysia, Jalan Raja Muda Abdul Aziz, 50300 Kuala Lumpur, Malaysia. E-mail: drtasyatarib@yahoo.com

\section{INTRODUCTION}

Significant changes in esthetics demand and dental materials significantly affect the dental education system. Teaching conventional crown preparation cannot be considered adequate for modern dental practitioner. The purpose of every curriculum is to provide the graduating dental students with a well-rounded, balanced educational experience and the preclinical and clinical exposure necessary for competence. ${ }^{1}$ Changes in dental materials significantly affect the treatment options a dentist could provide to the patients. The list of new procedures and materials includes bonded restorations and prostheses and new porcelains that are strong to resist high occlusal forces. $^{2}$

Dental students are responsible for the provision of invasive, irrevocable treatment of patients in their care. Thus, they are required to develop the knowledge, skills and attitudes necessary to equip them to be competent and independent practitioners after their undergraduate years. Dental educators can only give so much to the students; it is the students' responsibility and effort to make the full use of it. The assessment of students' knowledge and skills is important to educators as it is worth noting that their teaching methods are effective in producing a competent dental student. Before dental students enter their clinical session, they have to undergo the preclinical session where they will perform the required tasks on frasaco or plastic teeth. The assessment of the preclinical performance is essential for patient's safety, as well as to provide feedback on the teaching methods. ${ }^{3}$

Fixed prosthodontic course in Faculty of Dentistry Universiti Kebangsaan Malaysia (UKM) is introduced to the undergraduates during the $4^{\text {th }}$ year of study. Students are expected to complete certain tasks in the preclinical session before they are allowed to treat patients with fixed prosthodontic prostheses. The session usually runs for 5 weeks and it consists of 10 hours of lectures and 30 hours of simulation clinic together with 4 hours of video and live demonstrations. Didactic part of the course is given, including case managements. The simulation clinic is performed with a system that consists of a manikin head connected to artificial jaws containing frasaco teeth. The head is attached to a torso which height can be adjusted. The system also includes a swiveling delivery unit, with dental handpieces and light. Students are presented with video demonstrations on the particular task for the session. Throughout the session, students are also shown the models, clinical and laboratory photos, as well as types of bur that they need for the preparation. At the end of the session, students will show the prepared teeth to their supervisors, and it then be evaluated using a validated criteria evaluation form (Table 1).

For the preparation of all ceramic crown (ACC), students were given 1-hour of lecture and 6 hours of simulation clinic. They were shown a 45 minutes long video 
Table 1. Criteria of assessment for crown preparation

\begin{tabular}{|c|c|c|c|c|}
\hline & $\begin{array}{c}\text { Excellent } \\
3\end{array}$ & $\begin{array}{c}\text { Good } \\
2\end{array}$ & $\begin{array}{c}\text { Poor } \\
1\end{array}$ & $\begin{array}{c}\text { Unacceptable } \\
0\end{array}$ \\
\hline $\begin{array}{l}\text { Path of } \\
\text { insertion or } \\
\text { withdrawal }\end{array}$ & $\begin{array}{l}\text { No undercut present } \\
\text { in the preparation } \\
\text { (s). }\end{array}$ & $\begin{array}{l}\text { Slight undercut } \\
\text { present in one of the } \\
\text { preparation(s) wall. }\end{array}$ & $\begin{array}{l}\text { Undercuts present in } \\
\text { preparation(s), but the defect } \\
\text { is correctable with additional } \\
\text { preparation. }\end{array}$ & $\begin{array}{l}\text { Undercut defect is major } \\
\text { and must be corrected with } \\
\text { root canal treatment or } \\
\text { other means of treatment. }\end{array}$ \\
\hline $\begin{array}{l}\text { Resistance } \\
\text { and retention }\end{array}$ & $\begin{array}{l}\text { Optimum resistance } \\
\text { and retention present } \\
\text { in preparation(s). } \\
\text { Bridge preparation } \\
\text { must draw. }\end{array}$ & $\begin{array}{l}\text { Abutment(s) have } \\
\text { sufficient resistance and } \\
\text { retention. Bridge may } \\
\text { not draw. }\end{array}$ & $\begin{array}{l}\text { Resistance and retention has } \\
\text { been compromised because } \\
\text { preparation(s) is over tapered. } \\
\text { Other form of resistance } \\
\text { and retention is needed and } \\
\text { can be attained with further } \\
\text { preparations. }\end{array}$ & $\begin{array}{l}\text { Resistance and retention } \\
\text { has been compromised. } \\
\text { Other methods of } \\
\text { treatment is needed to } \\
\text { attain an acceptable } \\
\text { situation i.e. root canal } \\
\text { treatment. }\end{array}$ \\
\hline $\begin{array}{l}\text { Structural } \\
\text { durability of } \\
\text { preparation } \\
\text { and } \\
\text { restoration }\end{array}$ & $\begin{array}{l}\text { Absolute structural } \\
\text { durability has been } \\
\text { produced. }\end{array}$ & $\begin{array}{l}\text { Acceptable tooth } \\
\text { preparation has been } \\
\text { performed to permit } \\
\text { functional restoration. } \\
\text { Conservative, no sharps } \\
\text { or unsupported areas, } \\
\text { and the surface of } \\
\text { preparation is smooth. }\end{array}$ & $\begin{array}{l}\text { Abutments need further } \\
\text { preparation to be acceptable. } \\
\text { Adjacent tooth has been } \\
\text { damaged. Abutments are } \\
\text { under or over prepared. } \\
\text { Preparation has sharp or } \\
\text { unsupported areas and surface } \\
\text { is rough. Further preparation } \\
\text { is needed. }\end{array}$ & $\begin{array}{l}\text { Abutments are over } \\
\text { prepared, tooth need root } \\
\text { canal treatment or alternate } \\
\text { preparation design is } \\
\text { required. Adjacent tooth } \\
\text { has been severely damaged } \\
\text { and need a restoration. }\end{array}$ \\
\hline $\begin{array}{l}\text { Finish line } \\
\text { (margin) }\end{array}$ & $\begin{array}{l}\text { Ideal margin } \\
\text { placement, form, } \\
\text { smoothness and } \\
\text { dimension in all } \\
\text { areas of the tooth. }\end{array}$ & $\begin{array}{l}\text { Margin is adequately } \\
\text { placed and identifiable, } \\
\text { smooth and continuous } \\
\text { with no steps. } \\
\text { Dimension of margin is } \\
\text { not ideal but acceptable. } \\
\text { Margin is located on the } \\
\text { sound tooth surface. }\end{array}$ & $\begin{array}{l}\text { Incorrect placement of } \\
\text { margin, with steps in some } \\
\text { areas, dimension of margin is } \\
\text { inadequate. Margin is located } \\
\text { on the existing restoration. } \\
\text { Further preparation is needed. }\end{array}$ & $\begin{array}{l}\text { Incorrect placement of } \\
\text { margin. Dimension of } \\
\text { margin is correctable with } \\
\text { further periodontal surgery } \\
\text { or orthodontic procedures. }\end{array}$ \\
\hline
\end{tabular}

demonstration on how to prepare ACC. The students were asked to evaluate their work as well, and the supervisor guided the student if there were major differences. The instructional outcome of this process was to develop selfassessment skills in a structured environment through a discriminative learning. ${ }^{4-6}$ It is believed that this process could help the students to be critical to their work.

For the crown preparation, students were taught the ideal preparation, where $6^{\circ}$ of tapered need to be achieved. Tapers ranging from $0^{\circ}$ to $16^{\circ}$ have been suggested over the years as it will provide optimum retentive walls for the extracoronal restorations as the tapered and parallelism of the axial walls will contribute to retention and resistance of the restorations. ${ }^{7,8}$ The students were taught to hold the rotary cutting bur so the ideal taper and parallelism could be achieved. As for the margins, students were taught to prepare shoulder margin for the ceramic. The amount of other reductions such as incisal reduction was taught to the students and they had to prepare putty indexes to evaluate the amount of tooth reductions. Guidelines of tooth preparation were followed from Goodacre et al. ${ }^{9}$

The objective of this study is to evaluate the quality of all ceramic crown preparations done by dental undergraduate students during their preclinical sessions before entering clinical session. The hypothesis for this research is that the preparation done would be moderately acceptable as they had no experience in ACC preparation, with close monitoring from the supervisors.

\section{MATERIALS AND METHODS}

Research information was given to $4^{\text {th }}$ year (batch 2005/2006) UKM dental undergraduates before proceeding the preclinical session. Written consent was obtained. A pilot study was conducted for calibration and the consistency was revealed using Cohen's kappa test.

One hundred and four plastic teeth, upper right central incisor (11) that have been prepared by $4^{\text {th }}$ year UKM dental undergraduates during the preclinical session for ACC were collected. The formulated exclusion criteria are teeth with attached provisional restoration, teeth with fungus and teeth with damaged or fractured surfaces.

The teeth were placed on the frasaco arches and then mounted in the frasaco head. The preparations were examined for tapering, presence of undercuts, reductions, location of margins and preparation of shoulder margin. A putty index was fabricated earlier using unprepared frasaco teeth to determine the amount of crown preparation reductions. These include incisal, buccal, palatal and 
interproximal reductions, together with biplanar reduction. Students were reminded to preserve the cingulum anatomy while preparing for palatal and cingulum reductions. All margins should be shoulder margin. The location of the margin should be at the gingival margin. The preparations were examined using hand instruments and visual. Evaluations were made based on the criteria of assessment for crown preparation.

Each preparation represented the effort of first time dental undergraduates preparing ACC preparation. They worked utilizing their understanding from the lectures and the video demonstration, together with visual understanding of the models given throughout the preclinical session. All preparations were completed by the students under clinical setting in the simulation clinic, where the frasaco arches were mounted in the frasaco head and students used protective gloves, masks and glasses. Students were also shown the correct body position for the preparation as well as how to angulate the bur while cutting the teeth to prevent creation of undercuts or over tapered of the axial walls.

Data collected were presented with descriptive statistics. Frequencies analyses and cross tabulations were included in presenting the data obtained.

\section{RESULTS}

Following the sample selection of 104 teeth, only $92(88.46 \%)$ plastic teeth were qualified to be included (Table 2).

Table 2. The result of samples selection

\begin{tabular}{lcc}
\hline \multicolumn{1}{c}{ Criteria samples } & Number & Percentage (\%) \\
\hline Attached provisional restoration & 10 & 9.62 \\
Teeth with fungus & 0 & 0 \\
Fractured or damaged teeth & 2 & 1.92 \\
Accepted teeth & 92 & 88.46 \\
Sample size & 104 & 100.00 \\
\hline
\end{tabular}

Overall results were presented in Table 3. Majority of the teeth $77(84 \%)$ had about right and acceptable tapered without the presence of undercuts. The remaining 15 teeth presented with poor and unacceptable tapered, either presented with undercut, or they were overly tapered. Biplanar preparation was evidenced on $89(97 \%)$ teeth. For axial and incisal reductions, majority of the teeth showed acceptable reductions, with 88 and 87 teeth respectively. The reductions would fulfill the structural durability component of the criteria. Cingulum wall preparation only evidenced in $53 \%$ of the sample. Margin of 90 teeth (98\%) were found to be located either on the gingival margin or supragingival, while 2 of the teeth showed subgingival margin. Margins located supragingivally and on gingival margin would be considered as acceptable. Shoulder margin was expected to be prepared buccal-palatally. 90 (98\%) teeth were prepared with shoulder margin buccally and $89(97 \%)$ palatally. The remaining teeth were prepared with chamfer margin. Examples of the teeth were presented in Figure 1 to Figure 4.

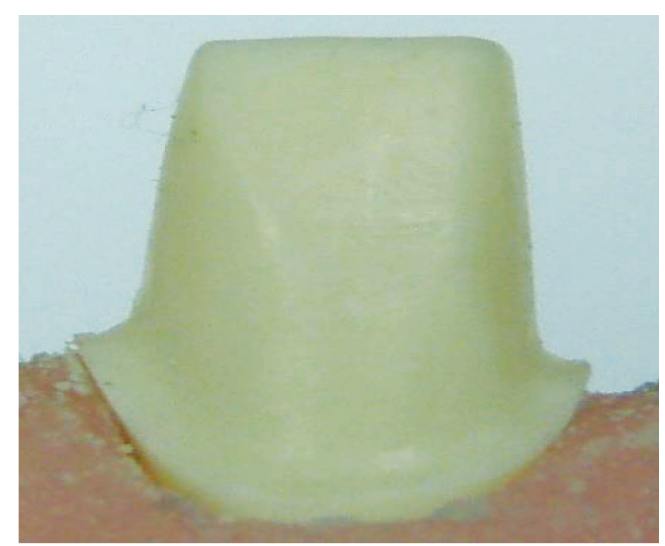

Figure 1. Margin located about $0.5 \mathrm{~mm}$ from the gingival margin.

Table 3. Overall results for crown evaluation based on criteria of assessment

\begin{tabular}{lcccc}
\hline \multirow{2}{*}{ Criteria } & \multicolumn{3}{c}{ Sample } \\
\cline { 2 - 4 } & \multicolumn{2}{c}{ Excellent and good (acceptable) } & Poor and unacceptable \\
\cline { 2 - 5 } & Number (n) & Percentage (\%) & Number (n) & Percentage (\%) \\
\hline Tapering of axial walls & 77 & 84 & 15 & 16 \\
Biplanar reduction & 89 & 97 & 3 & 3 \\
Structural durability & & & & 4 \\
- Axially & 88 & 96 & 5 & 5 \\
- Incisally & 87 & 95 & 43 & 47 \\
Cingulum wall & 49 & 53 & 2 & 2 \\
Margin location & 90 & 98 & 2 & 2 \\
Types of margin & & & 3 \\
- Buccally & 90 & 98 & 97 & 3 \\
\hline
\end{tabular}




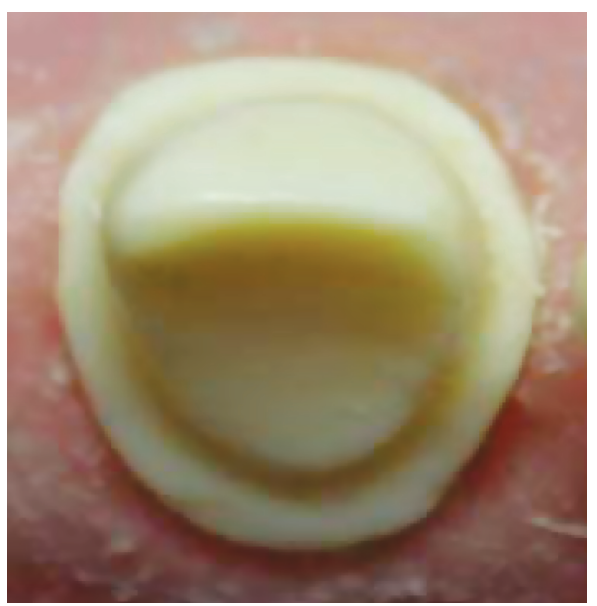

Figure 2. Shoulder margin were prepared around the tooth, continuously and smoothly.

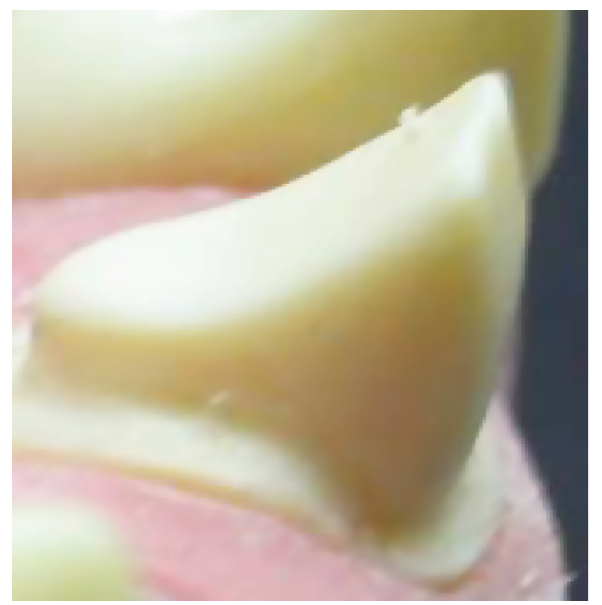

Figure 3. Acceptable cingulum wall height, contribute to retention and resistance, as well as structural durability.

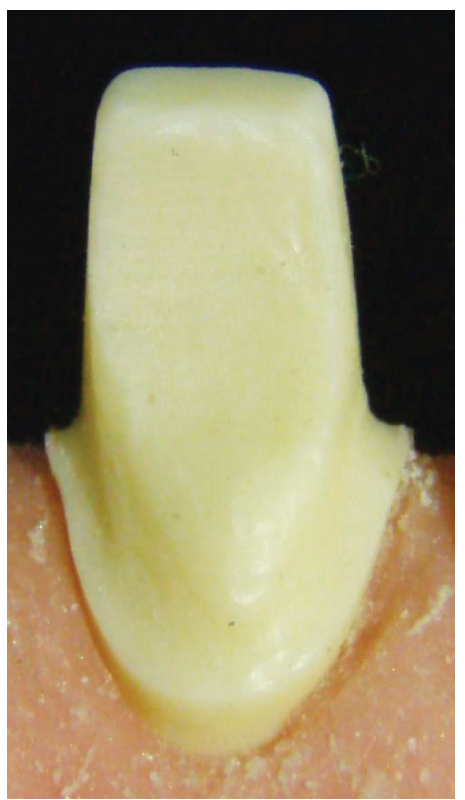

Figure 4. Acceptable tapered has been prepared in one of the sample.

\section{DISCUSSIONS}

Cosmetic dentistry has becoming more and more demanding. Patients nowadays opt for something that would improve their appearance. Therefore, dental undergraduates have to be prepared with the competence in preparing ceramic restorations.

Preclinical training in UKM includes the preparation of all ceramic crown. The students must be competent and confident in treating patients with this type of crown. It is overwhelming to learn that most of the students were on the right track in terms of the overall preparation. However they need to be reminded of the importance of preservation of cingulum wall as it would contribute to the retention and resistance aspect of the extracoronal restoration.

Tapering of the axial walls ranging from $0^{\circ}$ to $16^{\circ}$ have been suggested over the years as it will provide optimum retentive walls for the extracoronal restorations. ${ }^{7,8}$ The tapered and parallelism of the axial walls will ensure that the retention and resistance of the restorations are not compromised. In the present study, $84 \%$ of the sample showed acceptable tapered. The presence of undercut or overtapered may be due to the angulation of the bur during tooth preparation. Dental educators must stress out the importance of tapering to the undergraduates to fulfill one of the principles of tooth preparation. The presence of biplanar in tooth preparation would contribute to the structural durability of the extracoronal restoration. Most of the teeth showed biplanar reduction in the preparation.

Other reductions such as axial and incisal are as important as the preparation of the margin. Acceptable axial and incisal reductions were found in the present study, $96 \%$ and $95 \%$ respectively. Such reductions are important as the optimum bulk of material must be present in the restoration to prevent any fracture or perforation after cementation. Preservation of the cingulum would also contribute to the structural durability and prevention of pulpal exposure, as well as retention and resistance of the restoration. However, only $53 \%$ of the sample showed acceptable cingulum wall preparation. It may be due to the wrong angulation of the bur during preparation that lead to flat or unacceptable cingulum wall.

The ideal location of the margin must be supragingival or on the gingival margin. These would prevent any plaque accumulation as oral hygiene is easy to maintain. It would also contribute to the maintenance of the periodontium and preservation of biologic width. Almost all of the teeth presented with acceptable margin location, accounted for $98 \%$. Shoulder margin is expected to be prepared by the students buccal-palatally for all ceramic crown. Shoulder margin would provide enough bulk of ceramic at the margin as to prevent any fracture that could lead to microleakage of the extracoronal restoration. Only $2 \%$ of the sample did not present with shoulder margin buccally, and 3\% palatally.

Most of the crowns prepared by the students were acceptable. It showed that they understood the principles of crown preparation. Cingulum wall preparation has to 
be given more stress as it is important in the retention and resistance of the restoration.

\section{ACKNOWLEDGEMENT}

We would like to thank those who helped and supported us with this project, including students and Simulation Laboratory staffs. Special thanks to Madam Siti Zubaidah Anuar, CELPAD English language teacher of International Islamic University of Malaysia for proof reading this report.

\section{REFERENCES}

1. Ferguson MB, Sobel M, Niederman R. Preclinical restorative training. J Dent Educ 2002; 66(10):1159-63.
2. Seals RR Jr. Restorative and prosthetic dental education: Changes, challenges and opportunities. J Prosthodont 1993; 2(2):73-4.

3. Manogue M, Brown G, Foster H. Clinical assessment of dental students: values and practices of teachers in restorative dentistry. Medical Education 2001; 35:364-70

4. Knight GW, Walcott AM, Guenzel PJ. A paradigm for teaching a remedial preclinical course. J Dent Educ 1988; 52:558-61.

5. Knight GW, Guenzel PJ. Discrimination training and formative evaluation for remediating basic waxing skill. J Dent Educ 1990; 54:194-8.

6. Feil PH, Guenzel PJ, Knight GW. Theoritical foundations of motor skill performance and their applications to dental education. J Dent Educ 1994; 58:806-12.

7. Kent WA, Shillingburg HT, Duncanson MG. Taper in clinical preparations for cast restorations. Quintessence Int 1988; 19:339-45.

8. Shillingburg HT, Hobo S, Whitsett LD. Fundamentals of fixed prosthodontics $3^{\text {rd }}$ ed. Chicago IL: Quintessence Publishing; 1997. p. 119.

9. Goodacre JC, Campagni WV, Aquilino SA. Tooth preparations for complete crowns: and art form based on scientific principles. J Prosthet Dent 2001; 85:363-76. 